\title{
TGF- $\beta$ induces TIAF1 self-aggregation via type II receptor-independent signaling that leads to generation of amyloid $\beta$ plaques in Alzheimer's disease
}

\author{
M-H Lee ${ }^{1,11}$, S-R Lin ${ }^{1,11}$, J-Y Chang ${ }^{1,11}$, L Schultz ${ }^{2}$, J Heath ${ }^{2}$, L-J Hsu, ${ }^{3,4}$, Y-M Kuo ${ }^{5}$, Q Hong ${ }^{6}$, M-F Chiang ${ }^{7}$, C-X Gong ${ }^{8}$, C-I Sze ${ }^{\star, 5,9}$ \\ and N-S Chang , $, 1,2,4,10^{2}$
}

The role of a small transforming growth factor beta (TGF- $\beta$ )-induced TIAF1 (TGF- $\beta 1$-induced antiapoptotic factor) in the pathogenesis of Alzheimer's disease (AD) was investigated. TIAF1 physically interacts with mothers against DPP homolog 4 (Smad4), and blocks SMAD-dependent promoter activation when overexpressed. Accordingly, knockdown of TIAF1 by small interfering RNA resulted in spontaneous accumulation of Smad proteins in the nucleus and activation of the promoter governed by the SMAD complex. TGF- $\beta 1$ and environmental stress (e.g., alterations in pericellular environment) may induce TIAF1 selfaggregation in a type II TGF- $\beta$ receptor-independent manner in cells, and Smad4 interrupts the aggregation. Aggregated TIAF1 induces apoptosis in a caspase-dependent manner. By filter retardation assay, TIAF1 aggregates were found in the hippocampi of nondemented humans and AD patients. Total TIAF1-positive samples containing amyloid $\beta(A \beta)$ aggregates are 17 and $48 \%$, respectively, in the nondemented and AD groups, suggesting that TIAF1 aggregation occurs preceding formation of $A \beta$. To test this hypothesis, in vitro analysis showed that TGF- $\beta$-regulated TIAF1 aggregation leads to dephosphorylation of amyloid precursor protein (APP) at Thr668, followed by degradation and generation of APP intracellular domain (AICD), A $\beta$ and amyloid fibrils. Polymerized TIAF1 physically interacts with amyloid fibrils, which would favorably support plaque formation in vivo.

Cell Death and Disease (2010) 1, e110; doi:10.1038/cddis.2010.83; published online 23 December 2010

Subject Category: Neuroscience

Neurodegenerative diseases are frequently encountered in the aging populations in the human societies. The neuropathology of Alzheimer's disease (AD) is characterized by extracellular accumulation of fibrillar amyloid $\beta(\mathrm{A} \beta)$ peptide and intracellular deposition of neurofibrillary tangles made of cytoskeletal protein tau. ${ }^{1}$ These protein aggregates invoke neuronal death and block neurogenesis and learning and memory capabilities in AD patients.

Role of transforming growth factor beta (TGF- $\beta$ ) in the pathogenesis of $A D$ is controversial. ${ }^{2-5}$ Type II receptor for TGF- $\beta$ (T $\beta$ RII) is central to the TGF- $\beta$ /mothers against DPP homolog (Smad) signaling. Reduced levels of T $\beta$ RII are observed in human AD brains, and this correlates with age-dependent neurodegeneration and AD-like disease in a mouse model. ${ }^{2}$ However, in a transgenic AD mouse model, TGF- $\beta 1$ is constitutively upregulated and neuronal apoptosis occurs. ${ }^{3}$ Increased levels of TGF- $\beta$ in AD are associated with perivascular deposition of extracellular matrix, which hinders clearance of $\mathrm{A} \beta$ and allows the development of cerebral amyloid angiopathy. ${ }^{4}$ Blockade of TGF- $\beta /$ Smad innate immune signaling mitigates Alzheimer-like pathology in transgenic T $\beta$ RII mouse model. ${ }^{5}$

Here, we identified TGF- $\beta 1$-induced antiapoptotic factor (TIAF1) protein aggregation, which may cause neuronal death. TIAF1, a $12-\mathrm{kDa}$ TIAF1 ${ }^{6}$ participates in TGF- $\beta$ signaling ${ }^{7}$ and controls p53 activation. ${ }^{8}$ TIAF1 is implicated in the activation of $\mathrm{TH} 2$ helper T lymphocytes in chronic organ rejection ${ }^{9}$ and development of regulatory T cells, ${ }^{10}$ as well as

\footnotetext{
${ }^{1}$ Institute of Molecular Medicine, National Cheng Kung University College of Medicine, Taiwan, ROC; ${ }^{2}$ Guthrie Research Institute, Laboratory of Molecular Immunology, Sayre, PA, USA; ${ }^{3}$ Department of Medical Laboratory Science and Biotechnology, National Cheng Kung University College of Medicine, Taiwan, ROC; ${ }^{4}$ Center for Gene Regulation and Signal Transduction Research, National Cheng Kung University College of Medicine, Taiwan, ROC; ${ }^{5}$ Department of Anatomy and Cell Biology, National Cheng Kung University College of Medicine, Taiwan, ROC; ${ }^{6}$ Deptartment of Pulmonary Medicine, Zhongshan Hospital, Fudan University, Shanghai, China; ${ }^{7}$ MacKay Memorial Hospital, Taiwan, ROC; ${ }^{8}$ Department of Neurochemistry, New York State Institute for Basic Research in Developmental Disabilities, Staten Island, NY, USA; ${ }^{9}$ Department of Pathology, National Cheng Kung University College of Medicine, Taiwan, ROC and ${ }^{10}$ Department of Neuroscience and Physiology, SUNY Upstate Medical University, Syracuse, NY, USA

${ }^{*}$ Corresponding authors: N-S Chang, Institute of Molecular Medicine, National Cheng Kung University College of Medicine, 1 University Road, Tainan, Taiwan 70101, ROC. Tel: + 88662353535 Extn 5268; Fax: + 8866209 5845; E-mail: changns@ @mail.ncku.edu.tw or C-I Sze, Department of Anatomy and Cell Biology, National Cheng Kung University College of Medicine, 1 University Road, Tainan, Taiwan 70101, ROC. Tel: + 88662353535 Extn 5329; Fax: + 88662093007 ;

E-mail: szec@mail.ncku.edu.tw

${ }^{11}$ These authors contributed equally to this work.

Keywords: TIAF1; amyloid beta; aggregation; plaque; TGF- $\beta$

Abbreviations: TGF- $\beta$, transforming growth factor beta; TIAF1, TGF- $\beta 1$-induced antiapoptotic factor; TIAF1(E22/23A), TIAF1 with Glu22 and 23 mutated to Ala acting as dominant negative; AD, Alzheimer's disease; TNF, tumor necrosis factor; A $\beta$, amyloid $\beta ; \mathrm{T} \beta \mathrm{RII}$, type II TGF- $\beta$ receptor; APP, amyloid precursor protein; AICD, APP intracellular domain; SMAD, mothers against DPP homolog 4; PS1, presenilin 1; TIAF1si, small interfering RNA-targeting TIAF1; EYFP, enhanced yellow fluorescence protein; ECFP, enhanced cyan fluorescence protein; EGFP, enhanced green fluorescence protein; WOX1 (WWOX or FOR), WW domain-containing oxidoreductase; FRET, Förster/fluorescence resonance energy transfer; FRETc, FRET concentration; AO antibody, fibril-specific antibody; A11 antibody, A $\beta$ oligomer antibody; HAase, hyaluronidase; Hyal-2, hyaluronidase type 2; E2, $17 \beta$-estradiol

Received 10.2.10; revised 26.10.10; accepted 28.10.10; Edited by A Verkhrasky
} 
association with Hirschsprung's disease. ${ }^{11}$ TIAF1 tends to aggregate, and the protein aggregates are found in the hippocampi of postmortem nondemented humans and AD patients. Importantly, TIAF1 self-aggregation leads to generation of $\mathrm{A} \beta$ and amyloid fibrils from amyloid precursor protein (APP) in vitro.

\section{Results}

TIAF1 binds and blocks Smad4-dependent promoter activation. TIAF1 is an effector of the TGF- $\beta$ signaling. ${ }^{6-8}$ By yeast two-hybrid analysis, ${ }^{8,12-14}$ we determined that TIAF1 physically interacted with Smad4 (Figure 1a). Stimulation of COS7 fibroblasts with TGF- $\beta 1$ for $30 \mathrm{~min}$ resulted in the binding of endogenous TIAF1 with Smad4, and the complex was accumulated in the nuclei (Figure 1b).

COS7 cells were infected with a retroviral small interfering RNA-targeting TIAF1 (TIAF1si) or an empty retrovirus. ${ }^{8}$ After $48 \mathrm{~h}$, spontaneous relocation of Smad3 and 4 in the nuclei occurred in TIAF1-knockdown cells, but not in control cells, as determined by immunofluorescence microscopy (Figure 1c). Similarly, COS7 cells were transfected with enhanced green fluorescence protein (EGFP)-Smad4 plasmid and simultaneously infected with retroviral TIAF1si or empty retrovirus. Spontaneous accumulation of EGFP-Smad4 in the nuclei was observed in TIAF1-knockdown cells in $48 \mathrm{~h}$ (Figure 1d). Also, human monocytic U937 cells and mouse L929 fibroblasts were infected with retroviral TIAF1si or empty retrovirus and cultured for $48 \mathrm{~h}$. Smad3 and 4 were spontaneously accumulated in the nuclei of TIAF1-knockdown cells (Figures $1 \mathrm{e}$ and $\mathrm{f}$ ). Approximately $70 \%$ of endogenous TIAF1 protein was knocked down (Figures 1c-f).

In comparison, COS7 cells were transfected with enhanced cyan fluorescence protein (ECFP)-TIAF1 or ECFP alone and cultured for $24 \mathrm{~h}$. The cells were treated with TGF- $\beta 1$ for $1-8 \mathrm{~h}$, and stained with indicated specific antibodies. At hour 4, TIAF1 effectively blocked TGF- $\beta$ 1-mediated nuclear accumulation of Smad4 ( $<10 \%$ nuclear localization) and Smad2/3 (35-40\% nuclear localization) (Figure $1 \mathrm{~g}$ ). Similar results were observed at hour 8 . In control ECFP cells, TGF- $\beta 1$ induced nuclear accumulation of Smads was approximately 70-80\% (Figure 1g).

To determine TIAF1 regulation of SMAD-governed promoter activation, COS7 cells were co-transfected with ECFPTIAF1 and ECFP-Smad4 constructs (cyan fluorescence), along with a GFP reporter construct containing a SMADresponsive element or promoter. ${ }^{14}$ Cells were then cultured for $48 \mathrm{~h}$. Smad4 alone induced promoter activation (Figure 1h). In combination, TIAF1 significantly blocked the promoter activation $\left({ }^{\star} P<0.001, n=3, \sim 200\right.$ cells counted per experiment; Student's $t$ test) (Figure $1 \mathrm{~h})$. TIAF1 or ECFP alone had no effect on activating the SMAD-responsive element. Both negative and positive controls were shown (Figure 1h).

In TIAF1-knockdown cells, spontaneous activation of the SMAD-responsive element occurred ( 1.5-fold increase; Figure 1i). Also, ectopic Smad4-regulated promoter activation was significantly increased in the TIAF1-knockdown cells ( 2-fold increase; Figure 1i). Altogether, TIAF1 physically interacts with Smad4 and is likely to regulate Smad4 relocation and its transcriptional function.

TIAF1 self-binding induces apoptosis. To determine TIAF1 in TGF- $\beta 1$-regulated growth suppression, TGF- $\beta$ sensitive mink lung Mv1Lu epithelial cells were transfected with a mixture of ECFP and enhanced yellow fluorescence protein (EYFP) (yellow), or ECFP-TIAF1 and EYFP-TIAF1 plasmids by liposome-based GeneFector. Protein-protein interactions were measured by FRET (Förster/fluorescence resonance energy transfer) microscopy. TGF- $\beta 1$ rapidly induced apoptosis of cells overexpressing TIAF1/TIAF1 in $1 \mathrm{~h}$, but had no effect on ECFP/EYFP-expressing cells or non-transfected cells in time-lapse microscopy (Figure 2a). No apoptosis was observed in cells overexpressing a dominant-negative TIAF1(E22/23A) (TIAF1 with Glu22 and 23 mutated to Ala acting as dominant negative) alone (Figure 2a), and/or wild-type TIAF1 (Supplementary Figure S1). Similarly, human neuroblastoma SK-N-SH cells overexpressing TIAF1/TIAF1 were sensitive to UV lightinduced apoptosis, whereas ECFP/EYFP-overexpressing cells were resistant (Figure $2 b$ ).

TGF- $\beta 1$-induced TIAF1 self-binding occurs independently of T $\beta$ RII. In T $\beta$ RII-expressing cells, TGF- $\beta 1$ cross-links with $\mathrm{T} \beta \mathrm{R}$ Il for recruiting $\mathrm{T} \beta \mathrm{RI}$ (type I receptor) and signaling via the Smad2/3/4 complex. Human colon HCT116 cells are deficient in T $\beta$ RII. ${ }^{14}$ TGF- $\beta 1$ binds membrane hyaluronidase type 2 (Hyal-2) for recruiting tumor suppressor WW domain-containing oxidoreductase (WOX1) (also named WWOX or FOR) and Smad4 to relocate to the nuclei, which may dramatically increase the transcriptional activation for SMAD and apoptosis. ${ }^{14}$ HCT116 cells were transiently overexpressed with TIAF1/TIAF1 and the cells became sensitive to TGF- $\beta 1$-induced apoptosis (Figure $2 \mathrm{c}$ ). We determined that when TGF- $\beta 1$ increased the association of TIAF1/TIAF1 by $\sim 100 \%$ in FRET concentration (FRETc), cells underwent apoptosis (left panel, Figure 2c). When cells were co-transfected with TIAF1 and Smad4, no apoptosis was observed (right panel, Figure 2c). The expression of Smad4 was adjusted to a low level, so as to prevent apoptosis by ectopic Smad4.

TIAF1 self-binding induces apoptosis essentially in every cell dependently of caspases. Transient overexpression of TIAF1 is sufficient to sensitize cells to TGF$\beta 1$-mediated apoptosis. Human lung $\mathrm{NCl}-\mathrm{H} 1299$ cells were transfected with EYFP-TIAF1 only. TGF- $\beta 1$-induced TIAF1 aggregation (see punctates) and apoptosis in cells in a time-dependent manner (Supplementary Figure 3a and Supplementary Video 1). EYFP alone had no effect. Similar results were observed using other types of cells, as well as using EGFP- or ECFP-tagged TIAF1 (data not shown).

TIAF1 self-binding is apparently a universal occurrence. When SK-N-SH, SH-SY5Y, Mv1Lu and NCl-H1299 cells were transiently overexpressed with TIAF1/TIAF1, apoptosis occurred significantly in $24 \mathrm{~h}$, compared with cells overexpressing ECFP/EYFP (measured at the SubG0/G1 phase; Figure 3b). Reduction by $\sim 50-75 \%$ in the G0/G1, S and $\mathrm{G} 2 / \mathrm{M}$ phases of the cell cycle was shown in cells 
a

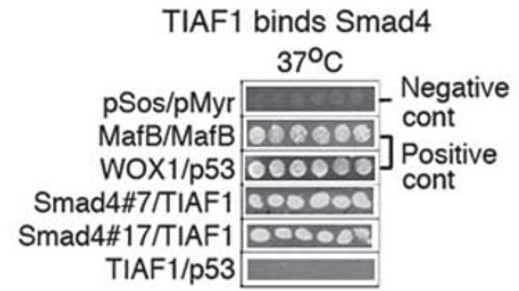

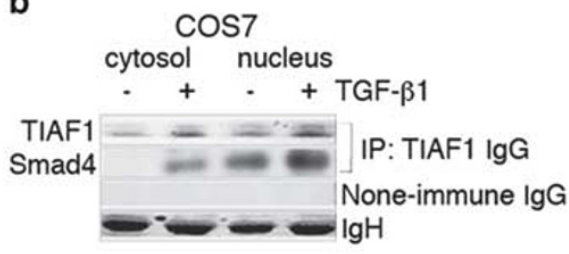
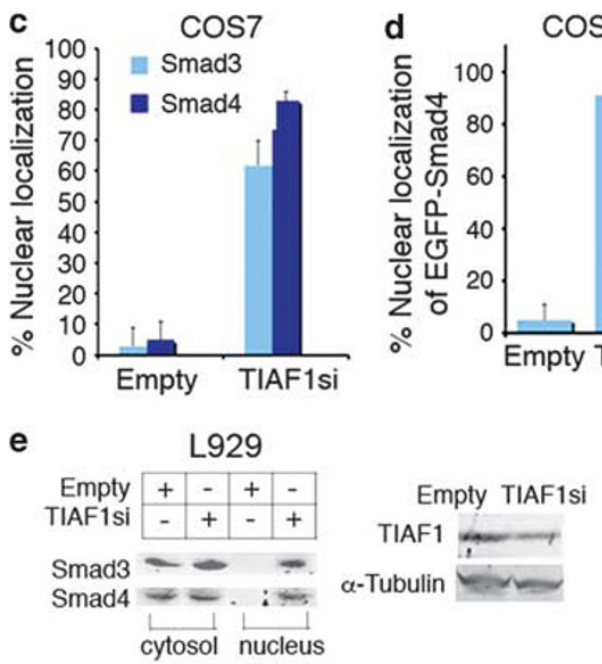

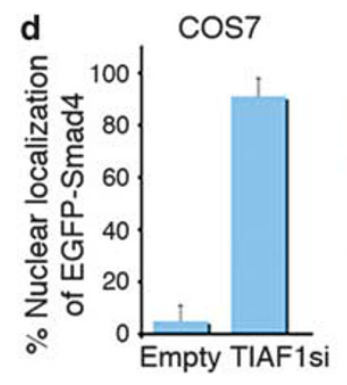

Smad4 TIAF1 nuclei merge

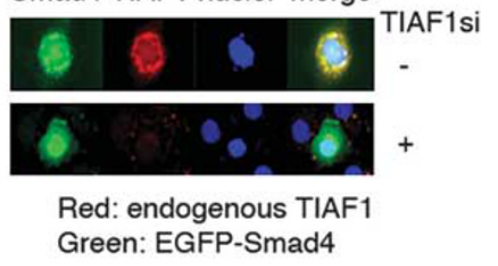

f
U937

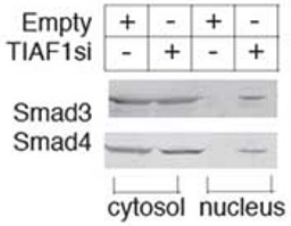

Empty TIAF1si

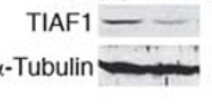

g

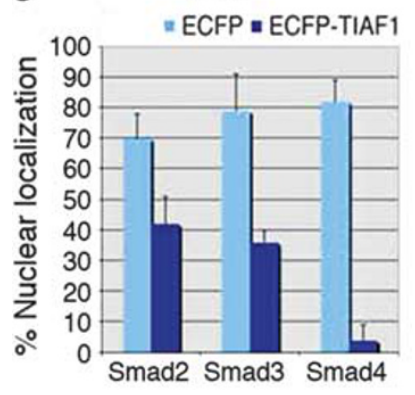

h

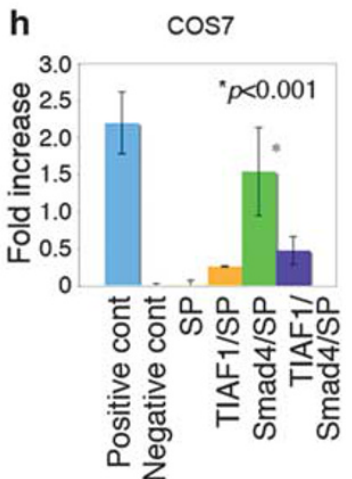

i

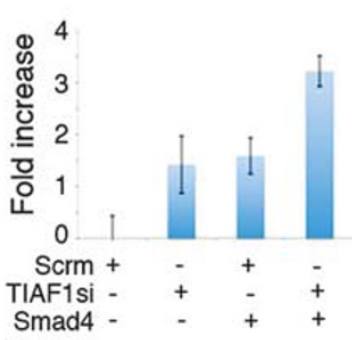

Figure 1 TIAF1 physically binds Smad4 and blocks Smad4-regulated promoter activation. (a) By yeast two-hybrid library screening, ${ }^{8,12,13}$ two Smad4 clones (No. 7 and 17), with an identical DNA sequence, were isolated as a TIAF1-binding protein. Both Smad4/TIAF1 interactions and positive control bindings for WOX1/p53 and MafB self-interaction are shown, as evidenced by the growth of yeast at $37^{\circ} \mathrm{C}$ using a selective galactose-containing agarose plate (six representative colonies). Empty pSos/pMyr vectors and p53/TIAF1 plasmid constructs, ${ }^{8,12,13}$ were regarded as negative controls. (b) COS7 cells were cultured in $10 \% \mathrm{FBS}$ and treated with or without TGF- $\beta 1$ (5 ng/ml) for $30 \mathrm{~min}$, followed by isolating cytosolic and nuclear fractions for co-immunoprecipitation with anti-TIAF1 lgG. TGF- $\beta 1$ increased the binding of TIAF1 with Smad4. Non-immune IgG was used as a negative control in co-immunoprecipitation. (c) COS7 cells were infected with retroviral TIAF1si or empty retrovirus and cultured for $48 \mathrm{~h}$, followed by determining protein nuclear localization for Smad3 and 4 by immunofluorescence microscopy. TIAF1si knocked down endogenous TIAF1 protein by 70\%. (d) COS7 cells were transfected with EGFP-Smad4 plasmid (using liposome) and infected with retroviral TIAF1si or empty retrovirus. The cells were grown for $48 \mathrm{~h}$, fixed and immunostained with TIAF1. Nuclei were stained with DAPI. Knockdown of TIAF1 significantly induced nuclear accumulation of EGFP-Smad4. (e and f) Human monocytic U937 cells and mouse L929 fibroblasts were infected with TIAF1si or empty retrovirus and cultured for $48 \mathrm{~h}$, followed by isolating nuclear and cytosolic fractions. Spontaneous accumulation of Smad3 and 4 in the nuclei was shown in cells infected with TIAF1si. Reduction of endogenous TIAF1 protein by siRNA is shown (60-75\% reduction; a representative set of data from two experiments). (g) COS7 cells were transfected with ECFP or ECFP-TIAF1 expression constructs, grown for $24 \mathrm{~h}$, and treated with TGF- $\beta 1$ (5 $\mathrm{ng} / \mathrm{ml}$ ) for $1-8 \mathrm{~h}$. The extent of accumulation of Smad2, 3 or 4 in the nuclei post TGF- $\beta 1$ treatment for $4 \mathrm{~h}$ is shown $(n=3, \sim 100$ cells counted per experiment), as determined by immunofluorescence microscopy. (h) COS7 cells were transfected with a SMAD-responsive element DNA construct (using GFP as a reporter), in the presence or absence of Smad4 and/or TIAF1 expression constructs. After $48 \mathrm{~h}$, positive promoter activation in cells with green fluorescence was counted. Compared with Smad4 alone, TIAF1 significantly blocked the ectopic Smad4-induced activation of the promoter $\left({ }^{*} P<0.001\right.$ for the last two bars at the right, $\sim 200$ cells counted in each experiment with three repeats; mean \pm S.D., Student's $t$ test). SP, promoter driven by SMAD. (i) COS7 cells were transfected with the SMAD promoter reporter construct and simultaneously infected with the TIAF1si or empty retrovirus. Knockdown of TIAF1 resulted in spontaneous activation of the SMAD promoter ( 1.5-fold increase). Ectopic Smad4-regulated promoter activation was increased by $\sim 2$-fold in the TIAF1-knockdown cells 


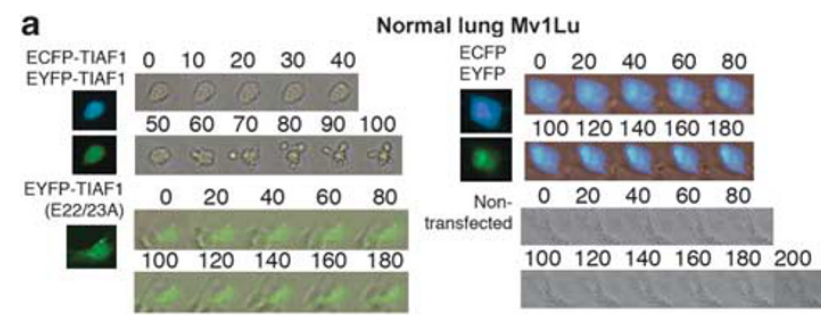

$$
\text { b }
$$

SK-N-SH

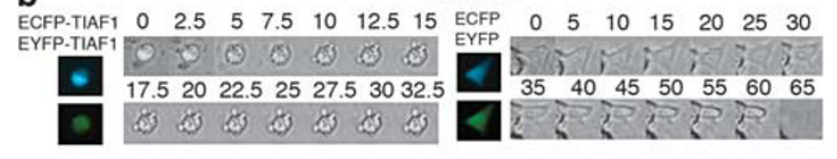

C

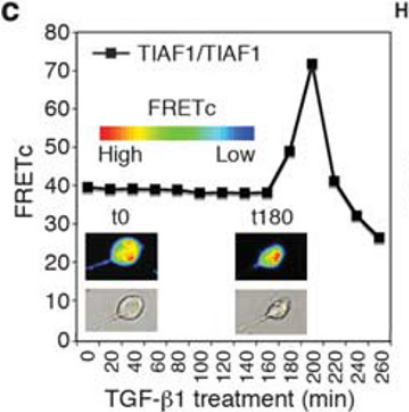

HCT116

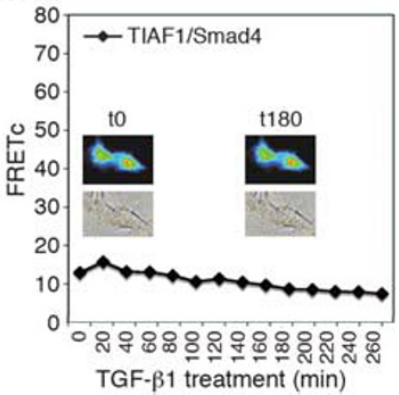

Figure 2 TIAF1 self-binding leads to apoptosis. (a) TGF- $\beta$-sensitive mink lung Mv1Lu epithelial cells, overexpressing ECFP/EYFP, ECFP-TIAF1/EYFP-TIAF1 or EYFP-TIAF1(E22/23A), were exposed to TGF- $\beta 1(5 \mathrm{ng} / \mathrm{ml})$. Time-lapse microscopy was carried out (total $8 \mathrm{~h}$; one picture taken per $5 \mathrm{~min}$ ). TGF- $\beta 1$ rapidly induced apoptosis of TIAF1/TIAF1-expressing cells, but not ECFP/EYFPexpressing cells, in $1 \mathrm{~h}$. No apoptosis was observed in cells overexpressing a dominant-negative TIAF1(E22/23A) or in non-transfected cells. (b) Human neuroblastoma SK-N-SH cells overexpressing TIAF1/TIAF1 were sensitive to UV light-induced apoptosis, but ECFP/EYFP-overexpressing cells were resistant. (c) Human T $\beta$ RII-deficient colon HCT116 cells, overexpressing TIAF1/TIAF1, were treated with TGF- $\beta 1(5 \mathrm{ng} / \mathrm{ml})$ and imaged by time-lapse FRET microscopy. TGF- $\beta 1$ significantly increased the self-binding of TIAF1/TIAF1 (left panel). When the binding reached a maximal strength (measured as FRETc), ${ }^{14}$ the cell underwent apoptosis (left panel). When cells were co-transfected with TIAF1 and Smad4, apoptosis was blocked (right panel). The expression of Smad4 was optimized to a low level, so as to prevent apoptosis by the overexpressed Smad4 (see Figure 3)

overexpressing TIAF1/TIAF1, compared with cells overexpressing ECFP/EYFP or nothing. These observations were reproduced in human breast cancer MCF7 and MDA-MB-231 cells, prostate DU145 cells, Jurkat T lymphocytes and murine L929 fibroblasts. TIAF1 self-binding-mediated cell death was blocked by a pan-caspase inhibitor zVAD-FMK (30 $\mu \mathrm{M}$; inhibition by $85 \%)$.

When TIAF1/TIAF1-expressing NCl-H1299, MCF7 and SK-N-SH cells were exposed to TGF- $\beta 1$ or $-\beta 2$ for $24 \mathrm{~h}$, no enhanced cell death (SubG1 phase) and growth suppression (G0/G1 phase) were observed (Supplementary Figures S2-S4). Indeed, during exposure of TIAF1/TIAF1-overexpressing cells to TGF- $\beta 1$ for $<3 \mathrm{~h}$, there was an enhanced TIAF1 self-binding and cell death (Figures 2 and $3 b$ ). Beyond the initial time points, occurrence of cell death appears to depend on the extent of TIAF1 self-binding. Without binding interaction between the wildtype and mutant TIAF1, no cell death occurred (Supplementary Figure S1).
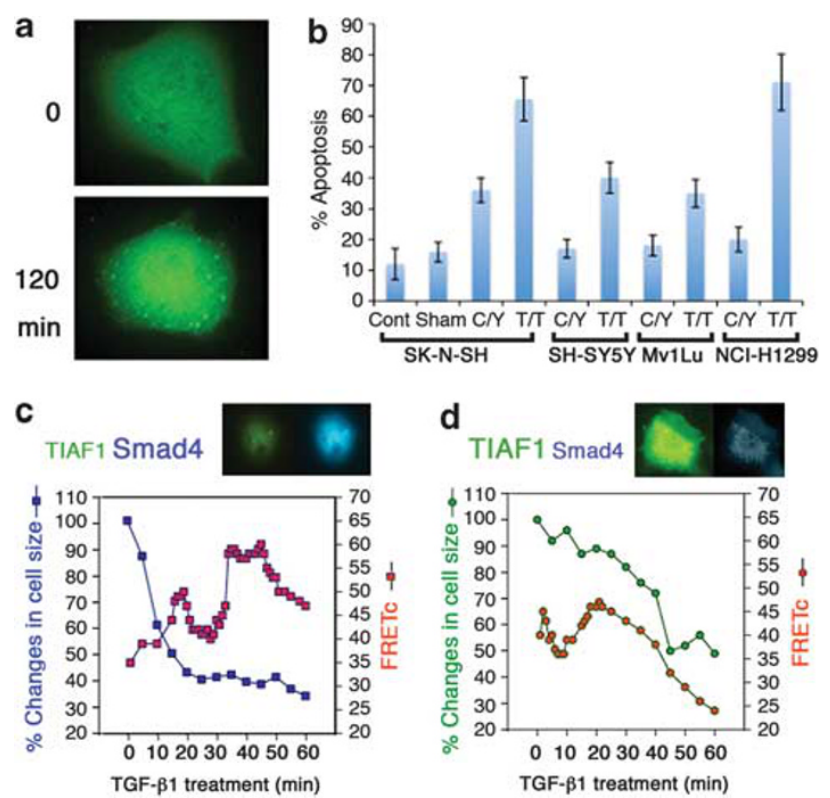

Figure 3 Smad4 regulates TIAF1 self-binding and cell fate. (a) TGF- $\beta 1$ $(5 \mathrm{ng} / \mathrm{ml})$ induced self-aggregation of TIAF1 (see green punctate formation), which leads to apoptosis of NCl-H1299 cells overexpressing EYFP-TIAF1, as determined by time-lapse microscopy. Also, see Supplementary Video 1. (b) Cell lines, including neuroblastoma SK-N-SH and SH-SY5Y cells, normal lung epithelial Mv1Lu cells, and lung cancer NCl-H1299 cells, were transfected with ECFP-TIAF1 and EYFPTIAF1 by electroporation and then cultured for $24 \mathrm{~h}$. These cells underwent apoptosis significantly, compared with cells overexpressing ECFP and EYFP (measured at the SubG0/G1 phase; $P<0.0005, n=3$, Student's $t$ test). Cont, control (no electroporation). Sham, electroporated with medium only. C/Y, ECFP and EYFP; T/T, ECFP-TIAF1 and EYFP-TIAF1. (c) When ECFP-Smad4 was expressed at a greater level than EYFP-TIAF1 in NCl-H1299 cells, TGF- $\beta 1$ $(5 \mathrm{ng} / \mathrm{ml})$ rapidly increased the binding of Smad4 with TIAF1 in 20 min (red color line for FRETc), and concurrently cell death occurred (reduction in cell size). (d) In contrast, cells became refractory to TGF- $\beta 1$-mediated apoptosis, when the expressed EYFP-TIAF1 level was higher than ECFP-Smad4. Under this condition, the binding affinity of these proteins was reduced

Smad4 prevents TIAF1 self-binding and determines cell fate. Whether Smad4 affects TIAF1 self-aggregation was examined. NCl-H1299 cells were transiently overexpressed with EYFP-TIAF1 and ECFP-Smad4. By time-lapse microscopy, when cells expressed a greater amount of Smad4 than TIAF1 (see big blue), they were highly sensitive to TGF- $\beta 1$-induced apoptosis, as evidenced by rapid cell shrinking and membrane blebbing (Figure 3c; see blue line). That is, TGF- $\beta 1$ activated the overexpressed Smad4 to cause apoptosis. ${ }^{15}$ TGF- $\beta 1$ rapidly increased the binding of TIAF1 with Smad4, followed by membrane blebbing and cell shrinking in $8 \mathrm{~min}$ (Figure $3 \mathrm{c}$; see red line). At the death phase, the strength of binding between Smad4 and TIAF1 reached maximally (30-50 $\mathrm{min})$, and the cell size reduced by greater than $60 \%$ (Figure 3c).

When cells expressed more TIAF1 protein than Smad4, they were refractory to TGF- $\beta 1$-induced apoptosis (Figure $3 d$; see green line). Although binding of TIAF1 with Smad4 was relatively weak (see red line), no self-aggregation of TIAF1 was observed (data not shown). Similar results were observed by testing HCT116 and L929 cells. 


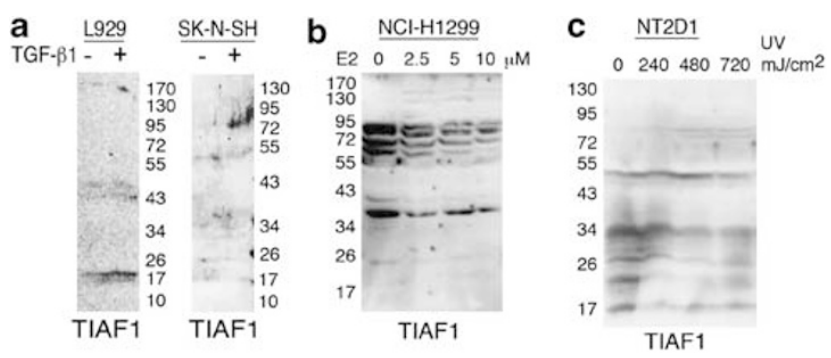

d

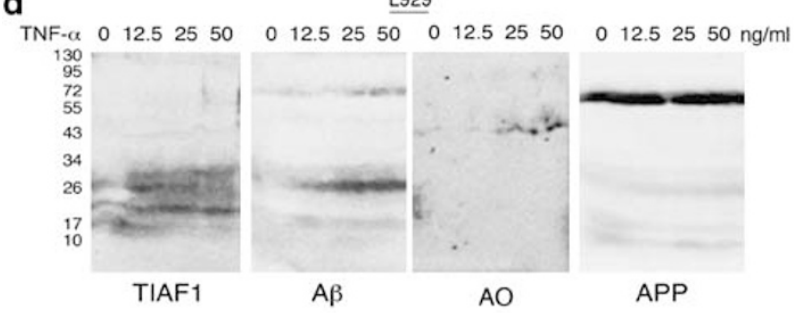

e

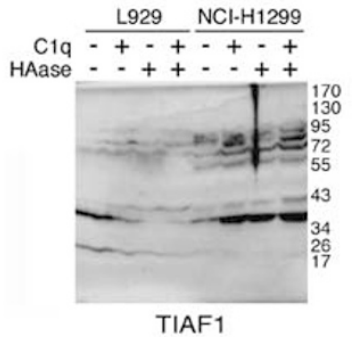

f HEK293 on NCl-H1299 matrix $\begin{array}{llllllll}\text { Prima1 } & 0 & 20 & 40 & 0 & 20 & 40 & \mathrm{mM}\end{array}$

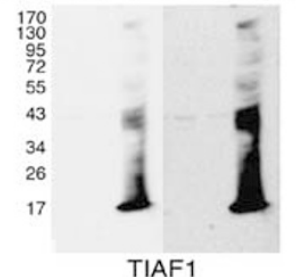

Figure 4 Extracellular stimuli induce TIAF1 self-polymerization. (a) L929 and SK-N-SH cells were grown to $80 \%$ confluence and then exposed to TGF- $\beta 1$ for $1 \mathrm{~h}$. TIAF1 expression was increased (12-17 kDa), along with the presence of high molecular size proteins. (b and $\mathbf{c}$ ) At high cell densities (100\% and higher), high molecular sizes of TIAF1 are shown in $\mathrm{NCl}-\mathrm{H} 1299$ and human teratocarcinoma NT2D1 cells. Estrogen (E2 or $17 \beta$-estradiol) blocked TIAF1 aggregation in $\mathrm{NCl}-\mathrm{H} 1299$ cells in $24 \mathrm{~h}$. UV irradiation rapidly suppressed the TIAF1 aggregation in NT2D1 cells in 90 min. (d) TNF- $\alpha$-induced TIAF1 polymerization in L929 cells in $1 \mathrm{~h}$ in a dose-related manner. Generation of $A \beta$ and amyloid fibrils was observed, as determined by monoclonal antibody against $A \beta$ (MCA2172) and fibril-specific AO antibody, ${ }^{36}$ respectively. (e) $\mathrm{L} 929$ and $\mathrm{NCl}-\mathrm{H} 1299$ cells were grown to $100 \%$ confluence (and even higher), pretreated with hyaluronidase $\mathrm{PH} 20$ (HAase; 200 units $/ \mathrm{ml}$ ) for $30 \mathrm{~min}$, and then exposed to purified complement C1q $(1 \mu \mathrm{g} / \mathrm{ml})$ for $1 \mathrm{~h}$. In resting cells, TIAF1 is expressed as monomeric $(17 \mathrm{kDa})$ and dimeric ( $35 \mathrm{kDa}$ ) forms in $\mathrm{L} 929$, but as a dimeric form in $\mathrm{NCl}-\mathrm{H} 1299$ (10\% reducing SDS-PAGE). Both C1q and HAase suppressed the TIAF1 expression in L929, but promoted formation of high molecular weight forms of TIAF1 in NCl-H1299. (f) $\mathrm{NCl}-\mathrm{H} 1299$ cells were cultured overnight on Petri dishes and then pretreated with or without Prima1 for $1 \mathrm{~h}$ (to restore mutant p53 function), ${ }^{16}$ followed by removal of cells using EDTA and repeat pipetting. HEK293 cells were then seeded on the matrix and grown for $24 \mathrm{~h}$. Superinduction of TIAF1 aggregation or polymerization was observed, especially when cells were grown on prima1-activated extracellular matrix. Exposure time, $15 \mathrm{~min}$ for left panel, and $30 \mathrm{~min}$ for right panel

UV light rapidly induced apoptosis of $\mathrm{NCl}-\mathrm{H} 1299$ cells overexpressing TIAF1/TIAF1. Reduction in cell size by $50 \%$ occurred at $20 \mathrm{~min}$, and membrane blebbing at $40 \mathrm{~min}$ (Supplementary Figure S5a). When cells were transfected with ECFP-TIAF1 and EYFP-Smad4, Smad4 limited the apoptotic response, in which membrane blebbing occurred at 76 min without reduction in cell size (Supplementary Figure S5b). In controls, cells were overexpressed with ECFP and EYFP only, and the kinetics showed that reduction in cell size by $50 \%$ occurred at $120-180 \mathrm{~min}$, and membrane blebbing at 200-240 min.

Extracellular stimuli induce TIAF1 self-polymerization. When L929 cells were grown to $80 \%$ confluence and then exposed to TGF- $\beta 1$ for $1 \mathrm{~h}$, TIAF1 expression was increased $(12-17 \mathrm{kDa})$, along with the presence of high molecular size proteins ( 43 and $46 \mathrm{kDa}$; Figure $4 \mathrm{a}$ ). Similarly, TGF- $\beta 1$ rapidly induced formation of large size TIAF1 (55 and $90 \mathrm{kDa}$ ) in SK-N-SH cells (Figure 4a). At high cell densities (100\% and higher), multiple molecular sizes of TIAF1 are shown in NCl-H1299 and human teratocarcinoma NT2D1 cells (Figures $4 \mathrm{~b}$ and c), as well as in COS7 and many other types of cells (data not shown). These observations are in parallel with the results from TGF- $\beta 1$-induced TIAF1 self-aggregation in real time (Figure 3a). On treatment with estrogen (E2 or $17 \beta$ estradiol) for $24 \mathrm{~h}$, TIAF1 aggregation was reduced in $\mathrm{NCl}$ H1299 cells (Figure 4b). Also, UV irradiation rapidly suppressed the aggregation in NT2D1 cells in $90 \mathrm{~min}$ (Figure 4c).

Tumor necrosis factor (TNF)- $\alpha$ rapidly induced TIAF1 polymerization in L929 cells in $1 \mathrm{~h}$ in a dose-related manner, which correlates with generation of $\mathrm{A} \beta$ and amyloid fibrils (Figure 4d). Monoclonal antibody against A $\beta$ (MCA2172), which was used in the entire experiments, did not cross-react with APP (Figure 4d, Supplementary Figures S6-S8). Also, APP antibody (MAB348) did not bind A $\beta$ (Figure 4d, Supplementary Figures S6 and S7). Amyloid fibrils were stained with Chemicon/Millipore's (Billerica, MA, USA) antibody against $\mathrm{A} \beta$ oligomers. Treatment of L929 cells with TGF- $\beta 1$, $-\beta 2$ and/or TNF- $\alpha$ for $24 \mathrm{~h}$ resulted in induction of high molecular sizes of TIAF1 and $\mathrm{A} \beta$ (Supplementary Figure S7). Failure of detection of $4.5 \mathrm{kDa} A \beta$ monomers was probably because of their release from the cells to the culture supernantants. ${ }^{15}$ By immunoprecipitation using specific antibodies against TIAF1 and $A \beta, A \beta$ monomer was enriched (Figures $6 \mathrm{~d}$ and $\mathrm{f}$ and $7 \mathrm{e}$ ).

When L929 cells were grown to a high cell density, TIAF1 became a dimer (Figure 4e). Both hyaluronidase PH20 and complement $\mathrm{C} 1 \mathrm{q}$ suppressed the expression of TIAF1 (Figure 4e). In contrast, NCl-H1299 cells expressed the dimeric TIAF1, and $\mathrm{C} 1 \mathrm{q}$ and $\mathrm{PH} 20$ promoted the formation of TIAF1 dimer, tetramer and higher molecular sizes (Figure 4e).

TIAF1 aggregation can be superinduced, especially when cells are cultured on the extracellular matrix derived from other types of cells pretreated with Prima1. p53-negative $\mathrm{NCl}-\mathrm{H} 1299$ cells were cultured overnight on Petri dishes and pretreated with or without Prima1 for $1 \mathrm{~h}$ (to restore mutant p53 function). ${ }^{16}$ The cells were then treated with 50 mM EDTA (in phosphate-buffered saline) at $4{ }^{\circ} \mathrm{C}$ for $5 \mathrm{~min}$, followed by removal using repeat pipetting. HEK293 cells were then seeded on the matrix and grown for $24 \mathrm{~h}$. When cells were grown on Prima1-activated extracellular matrix, superinduction of TIAF1 polymerization was observed (Figure 4f).

Similarly, p53-negative $\mathrm{NCl}-\mathrm{H} 1299$ cells were pretreated with pifithrin $\mu$ for $30 \mathrm{~min}$, and then exposed to hyaluronidase $\mathrm{PH} 20$ for $2 \mathrm{~h}$. HCT116 cells were seeded onto the extracellular matrices of $\mathrm{NCl}-\mathrm{H} 1299$ cells and grown for $48 \mathrm{~h}$. This resulted in TIAF1 polymerization and formation of $\mathrm{A} \beta$ and amyloid fibrils in HCT116 cells (Supplementary 
a
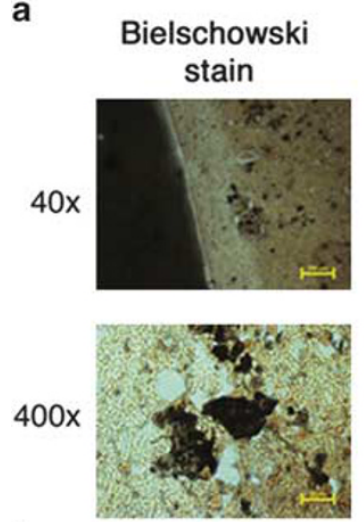

b

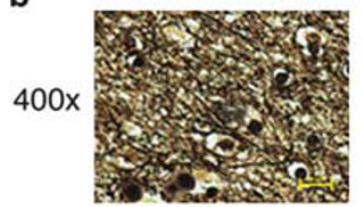

C

$400 x$

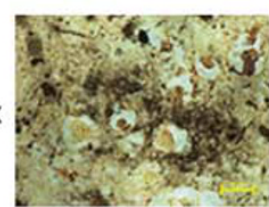

DAPI

TIAF1 Fluoro-Jade C
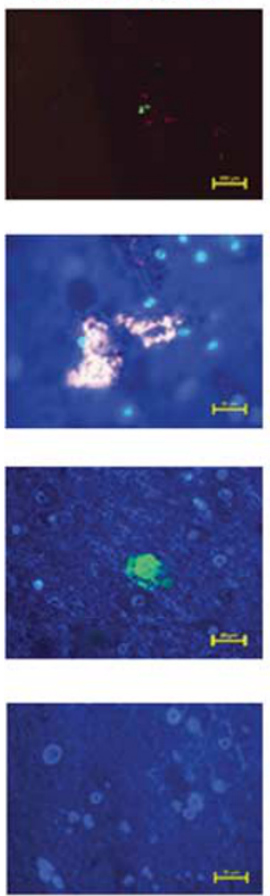

d

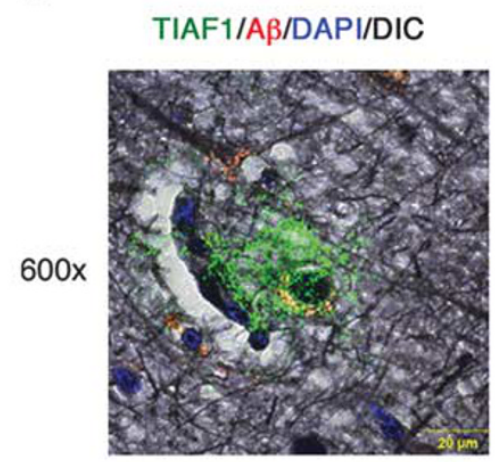

e TIAF1/AB/DAPI

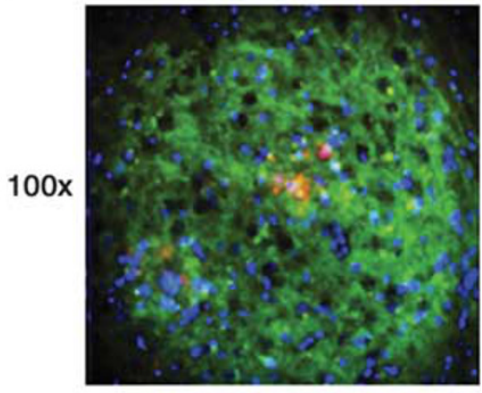

Figure 5 TIAF1 aggregates in degenerative neurons in the AD hippocampus. (a) Human hippocampal tissue sections were pre-stained with Bielschowski stain (containing silver), followed by staining with specific antibody against TIAF1. Fluoro-Jade C Red was used to identify degenerative neurons. Nuclei were stained with DAPI. Sequential magnification of aggregated TIAF1 (green; from $\times 40$ to $\times 400$ ) shows its colocalization with degenerative neurons (both in red and blue). (b) TIAF1 aggregation is shown in the extracellular matrix containing no signal for nuclei. (c) A representative negative control. The above sections were stained with a secondary antibody (green), Fluoro-Jade C Red and DAPI. Scale bars a-c, $20 \mu \mathrm{m}$ for $\times 400$ magnification, and $200 \mu \mathrm{m}$ for $\times 40$ magnification. (d) A confocal image of a plaque, containing TIAF1 and A $\beta$, is shown ( $\times 600$; also see data in Supplementary Figure S10). Scale bar, $20 \mu \mathrm{m}$ for $\times 600$ magnification. (e) A confocal image of a TIAF1 plaque, containing de novo synthesized A $\beta$ aggregates in the epicenter, is shown from the hippocampal section of an APP/PS1 transgenic mouse (also see Supplementary Figure S11)

Figure S8). Pifithrin $\mu$ is an inhibitor of p53 and blocks the binding of p53 with Bcl-xL. ${ }^{17}$

Finally, in rat primary glial cells, TIAF1 is expressed as 17- and 24-kDa proteins and high molecular sizes at a high cell density (Supplementary Figure S9). Lactacystin, a proteasome inhibitor, appeared to block TIAF1 expression (Supplementary Figure S9). Nocodazole, an inhibitor of microtubule polymerization, did not cause TIAF1 degradation. Together, lactacystin and nocodazole suppressed the expression of TIAF1 in $3 \mathrm{~h}$, without APP fragmentation and $\mathrm{A} \beta$ production (Supplementary Figure S9).

\footnotetext{
Identification of TIAF1 aggregates in human hippocampus. Postmortem human hippocampal tissue sections were pre-stained with Bielschowski stain (containing silver), followed by TIAF1 antibody ${ }^{6}$ and fluorescent IgG, as well as Fluoro-Jade $C$ to reveal degenerative neurons. ${ }^{18}$ Bielschowski stain demonstrated the presence of amyloid plaques in the human $A D$ hippocampus (Figures $5 a-c$ ). Degenerative neurons, positive with DAPI and Fluoro-Jade C staining, possess TIAF1 aggregates (Figure 5a). TIAF1 aggregates are shown in the extracellular matrix, without DAPIpositive cells (Figure 5b). In negative controls, secondary antibody only was used (Figure 5c). Confocal microscopy analysis showed that TIAF1 aggregates may or may not
}

colocalize with $\mathrm{A} \beta$ (Figure $5 \mathrm{~d}$; also see Supplementary Figure S10 for serial confocal sections). TIAF1 aggregates are normally $>100 \mu \mathrm{m}$ in diameter. Similar results were observed when using Abcam's (Cambridge, MA, USA) TIAF1 antibody (data not shown). TIAF1 aggregates were found in the interstitial tissue space in hippocampus and cortex, suggesting that TIAF1 is secreted and becomes aggregated.

TIAF1 aggregates in APP/presenilin 1 (PS1) or APP transgenic mice. We postulate the formation of TIAF1 aggregates preceding $A \beta$ in vivo. Expression of both proteins was investigated in the hippocampi of 9-month-old APP/PS1 and APP only transgenic mice. ${ }^{19}$ Many large size TIAF1 plaques ( $>100 \mu \mathrm{m}$ in diameter), containing small de novo synthesized $\mathrm{A} \beta$ in the epicenter, were observed in the hippocampus of APP/PS1 transgenic mouse (Figure 5e, Supplementary Figure S11). In contrast, presence of large size $\mathrm{A} \beta$ plaques, possessing small TIAF1 aggregates, was also observed in the mouse hippocampus. TIAF1 debris, rather than de novo synthesized materials, is shown (see white arrows; Supplementary Figure S12). Residual TIAF1 aggregates are located in the epicenter of an $\mathrm{A} \beta$ plaque (white arrow head). TIAF1 aggregation probably occurs in the hippocampus in the beginning followed by $\mathrm{A} \beta$ deposition, 

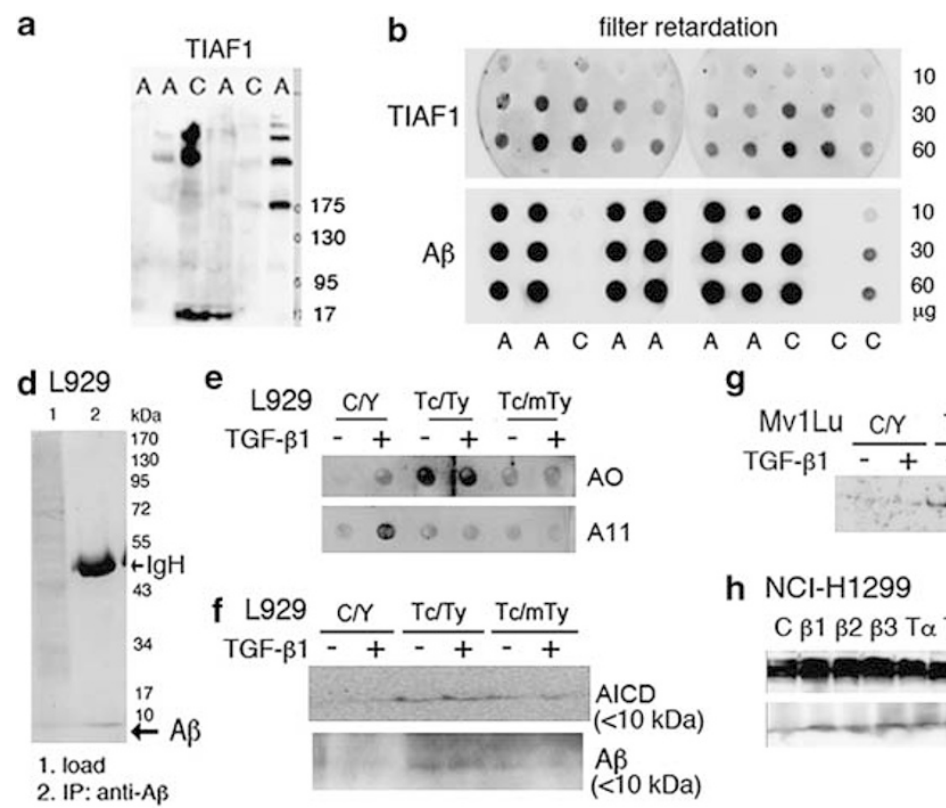

g

Mv1Lu $\frac{\mathrm{C} / \mathrm{T}}{-++} \frac{\mathrm{TC} / \mathrm{Ty}}{-+}$

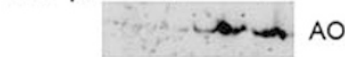

h $\mathrm{NCl}-\mathrm{H} 1299$

C $\beta 1 \beta 2 \beta 3 T \alpha T \beta$

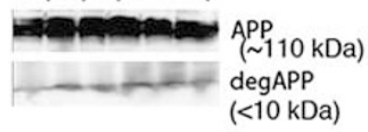

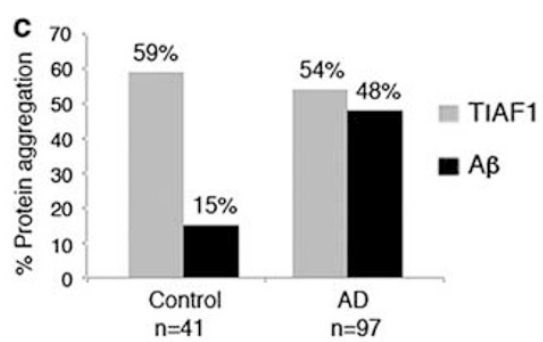

i

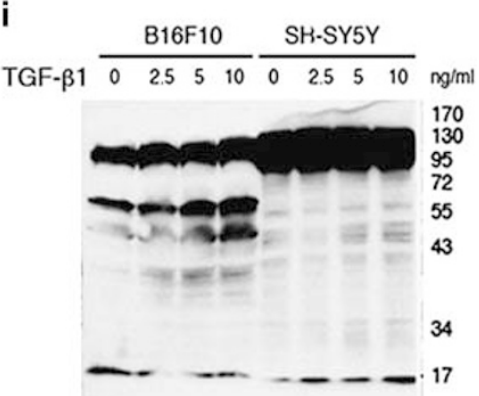

Figure 6 TIAF1 aggregation in vivo and generation of A $\beta$ in vitro. (a) Water-soluble TIAF1 protein aggregates were analyzed by non-reducing SDS-PAGE (5\%) and western blots using the lysates of hippocampal samples from postmortem AD patients and nondemented controls. The blots were stained with specific anti-TIAF1 antibody (also see Supplementary Figure S13). C, control; A, Alzheimer's disease. (b) Filter retardation assay shows the presence of 'water-insoluble' TIAF1 aggregates in control and AD hippocampi (representative data from 138 samples). The amounts of protein loaded were 10,30 and $60 \mu \mathrm{g}$, respectively, from top to bottom. (c) TIAF1 aggregation is shown in $59 \%$ of nondemented control hippocampi (age $59.0 \pm 17.0, n=41$ ), and only $15 \%$ of the total samples have A $\beta$ aggregates. In comparison, $54 \%$ of TIAF1 aggregation is shown in the hippocampi of older postmortem $A D$ patients $(80.0 \pm 8.8, n=97)$, and $48 \%$ of the total $A D$ samples possess $A \beta$ aggregates. In addition, there was $17 \%$ of the total TIAF1-positive samples possessing A $\beta$ aggregates in the control group, and $48 \%$ in the AD group. (d) L929 cells were treated with TNF- $\alpha$ ( $50 \mathrm{ng} / \mathrm{ml}$ ) for $24 \mathrm{~h}$. Presence of $\mathrm{A} \beta$ monomer ( $\sim .5 \mathrm{kDa}$ ) is weakly shown in the whole cell lysate (see load), and the band was enriched by immunoprecipitation using anti-A $\beta$ antibody (A $\beta \mathrm{H} 43$ ). (e and f) Transiently overexpressed ECFP-TIAF1/EYFP-TIAF1 (Tc/Ty) induced generation of amyloid fibrils (dot blot; AO antibody), AICD and A $\beta$ (reducing SDS-PAGE), but not in cells overexpressing ECFP/EYFP (C/Y) or ECFP-TIAF1/mutant EYFP-TIAF1 (Tc/mTy). TGF- $\beta 1$ ( $5 \mathrm{ng} / \mathrm{ml})$ induced the expression of prefibril A $\beta$ oligomers (A11 antibody) in C/Y-expressing L929 cells. Mutant or dominant-negative TIAF1 is with an E22/23A alteration. (g) Similar experiments were performed in Mv1Lu cells, which shows Tc/Ty-induced amyloid fibrils (a single band under reducing SDS-PAGE; $\sim 60 \mathrm{kDa}$ ). (h and i) NCl-H1299, B16F10 and SH-SY5Y cells were treated with medium C, TGF- $\beta 1$ $(5 \mathrm{ng} / \mathrm{ml}),-\beta 2(5 \mathrm{ng} / \mathrm{ml}),-\beta 3(5 \mathrm{ng} / \mathrm{ml})$, TNF- $\alpha(50 \mathrm{ng} / \mathrm{ml})$ and TNF- $\beta(25 \mathrm{ng} / \mathrm{ml})$ for $24 \mathrm{~h}$. Distinct APP degradation patterns are shown. A representative protein gel is shown from three repeats e-i

and that TIAF1 is likely to protect the formation of $\mathrm{A} \beta$ aggregates.

TIAF1 aggregates are abundant in the hippocampi of nondemented humans. Presence of TIAF1 aggregates is shown in water-soluble protein extracts of postmortem frozen human hippocampi by western blots (Figure 6a). Multiple aggregated TIAF1 forms are $>200 \mathrm{kDa}$ in both AD patients and nondemented controls (Figure 6a, Supplementary Figure S13). These aggregates are essentially devoid of ubiquitin, as determined in western blotting using the same blots (Supplementary Figure S13).

Filter retardation assay was carried out to determine the presence of water-insoluble TIAF1 aggregates $(>0.2 \mu \mathrm{m}$ in diameter) in human hippocampi. TIAF1 aggregation was present in $59.0 \%$ of postmortem nondemented human hippocampi (age 59.0 $\pm 17.0, n=41$ ), and $54 \%$ in older postmortem AD patients (age $80.0 \pm 8.8, n=97$ ) (Figure 6c). There were 15 and $48 \%$ for $\mathrm{A} \beta$ aggregates in controls and AD samples, respectively (Figure 6c). Further analysis revealed that there was only $17 \%$ of the total TIAF 1 -positive samples possessing $A \beta$ aggregates in the control group, and $48 \%$ for the AD group.
TIAF1 self-aggregation precedes production of $A \beta$ and amyloid fibrils. We validated the occurrence of TIAF1 aggregation preceding $\mathrm{A} \beta$ in vitro. Although $\mathrm{A} \beta$ monomer can be secreted from cells, we enriched the monomer by immunoprecipitation using anti- $\mathrm{A} \beta$ antibody $(\mathrm{A} \beta \mathrm{H} 43)$ in cell lysates (Figure $6 \mathrm{~d}$ or see Figure 7 ).

Transient overexpression of TIAF1/TIAF1 in L929 cells induced generation of amyloid fibrils ( $A O$ antibody), but not pre-fibrillar $A \beta$ oligomers ( $A 11$ antibody), as shown in dot blots (Figure 6e). Ectopic dominant-negative and wild-type TIAF1 did not generate amyloid fibrils (Figure 6e). The dominant negative did not bind wild-type TIAF1, as determined by FRET analysis. Interestingly, TGF- $\beta 1$ induced the expression of prefibrillar A $\beta$ oligomers in ECFP/EYFP-expressing L929 cells. Also, TIAF1/TIAF1-induced generation of APP intracellular domain (AICD) $(<10 \mathrm{kDa})$ and $A \beta(<10 \mathrm{kDa})$ (Figure $6 \mathrm{f})$. TIAF1/TIAF1 induction of amyloid fibril expression was shown in Mv1Lu cells (Figure 6g) and other cells such as HCT116, $\mathrm{NCl}-\mathrm{H} 1299, \mathrm{~B} 16 \mathrm{~F} 10, \mathrm{SK}-\mathrm{N}-\mathrm{SH}$ and SH-SY5Y cells (data not shown). In supporting experiments, $\mathrm{NCl}-\mathrm{H} 1299$ cells were treated with TGF- $\beta 1,-\beta 2,-\beta 3$, TNF- $\alpha$ or TNF- $\beta$ for $24 \mathrm{~h}$, and APP degradation occurred (Figure 6h). Exposure of B16F10 and SH-SY5Y cells to TGF- $\beta 1$ for $1 \mathrm{~h}$ showed distinct APP degradation patterns (Figure 6i). 
a

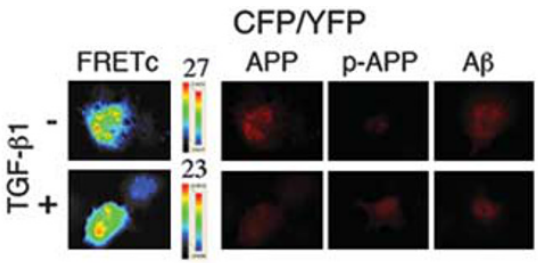

C

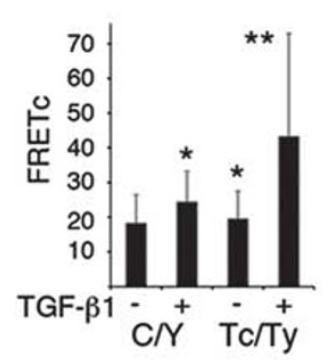

e

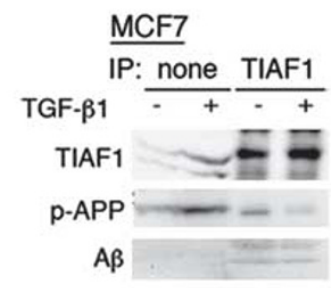

d

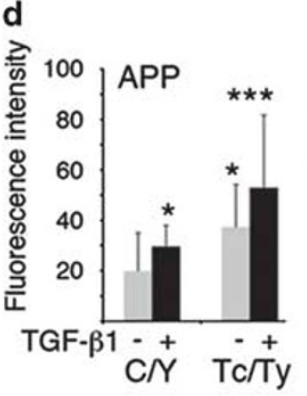

b TIAF1/TIAF1

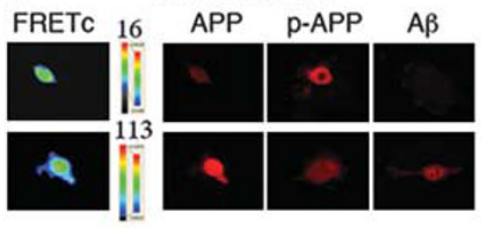

${ }^{*} p>0.05 ;{ }^{* \star} p<0.05 ;{ }^{\star \star \star} p<0.005$
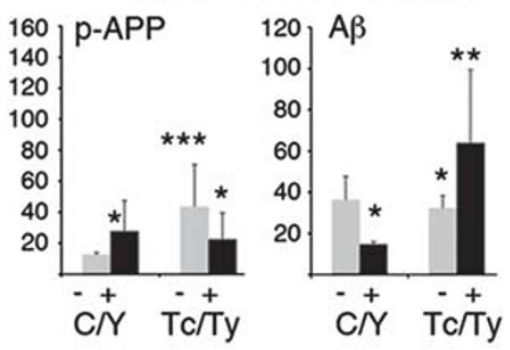

\section{f L929 IP: TIAF1}

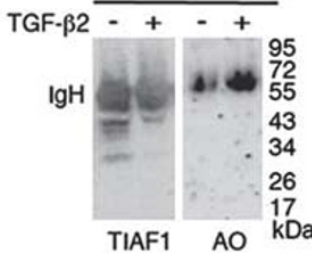

g

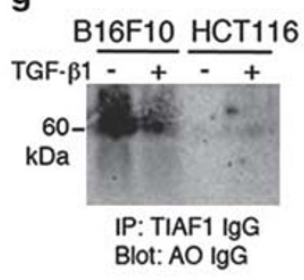

Figure 7 TGF- $\beta 1$ induces TIAF1 self-association, suppression of APP phosphorylation at Thr668, and A $\beta$ superinduction. (a and $\mathbf{b}$ ) SK-N-SH cells, overexpressing ECFP/ EYFP or ECFP-TIAF1/EYFP-TIAF1, were treated with TGF- $\beta 1(5 \mathrm{ng} / \mathrm{ml})$ for $24 \mathrm{~h}$, followed by determining the extent of protein self-binding by FRET microscopy. The expression of APP, APP phosphorylation at Thr668 and A $\beta$ was determined by fluorescent immunostaining. (c) FRET analysis was carried out from 10 assays (mean \pm S.D., $n=10$, Student's $t$ test: experiments versus non-treated C/Y controls). C/Y, ECFP/EYFP; Tc/Ty, ECFP-TIAF1/EYFP-TIAF1. (d) Comparison of protein expression profiles is shown (mean \pm S.D., $n=50$, Student's $t$ test: experiments versus non-treated $C / Y$ controls). (e) TGF- $\beta 1$ increased the phosphorylation of endogenous APP at Thr668 in MCF7 cells. By immunoprecipitation using specific TIAF1 antibody, TGF- $\beta 1$ suppressed the binding of TIAF1 with phosphorylated APP ( $\sim 70 \mathrm{kDa})$, but did not affect the binding of TIAF1 with A $\beta$ monomer. (f) TGF- $\beta 2$ increased the binding of TIAF1 with amyloid fibrils in L929 cells during treatment for $24 \mathrm{~h}$. IgH, IgG heavy chain. (g) In comparison, exposure of B16F10 cells to TGF- $\beta 1$ for $1 \mathrm{~h}$ caused reduction in the binding of TIAF1 with amyloid fibrils, whereas the effect was barely visible during this short-term experiment for HCT116 cells. L929, B16F10 and HCT116 were grown up to $100 \%$ confluence

SK-N-SH cells were overexpressed with TIAF1/TIAF1. On exposure to TGF- $\beta 1$ for $24 \mathrm{~h}$, cell sizes were reduced. These cells had significantly overexpressed APP and A $\beta$, compared with control cells (Figures 7a-d). FRET analysis showed that TGF- $\beta 1$ increased the self-binding of TIAF1 during treatment for $24 \mathrm{~h}$ (Figures $7 \mathrm{a}-\mathrm{d}$ ). Importantly, phosphorylation of endogenous APP at Thr668 was significantly increased in cells overexpressing TIAF1/TIAF1, and that TGF- $\beta 1$ suppressed the phosphorylation (Figure 7d). Increased phosphorylation at Thr668 in APP prevents cleavage by $\gamma$-secretase and generation of $A \beta 40 .{ }^{20}$

Finally, in western blotting, TGF- $\beta 1$ was shown to increase the phosphorylation of endogenous APP at Thr668, but suppressed the binding of TIAF1 with phosphorylated APP $(\sim 70 \mathrm{kDa})$ in MCF7 cells (Figure 7e). TGF- $\beta 1$ did not increase the binding of TIAF1 with A $\beta$ monomer (Figure 7e). Indeed, TIAF1 constantly bound a basal level of $A \beta$ monomer in COS7, L929 and other cells (data not shown). TGF- $\beta 2$ increased the binding of TIAF1 with amyloid fibrils in L929 cells during treatment for $24 \mathrm{~h}$ (Figure $7 \mathrm{f}$ ). However, exposure of B16F10 cells to TGF- $\beta 1$ for $1 \mathrm{~h}$ reduced the binding of TIAF1 with amyloid fibrils, whereas the effect was barely visible in HCT116 cells in this short-term experiment (Figure 7g).

\section{Discussion}

We have discovered for the first time that TIAF1 undergoes self-aggregation in response to TGF- $\beta 1$. TIAF1 participates in the TGF- $\beta$ signaling. Knockdown of TIAF1 with siRNA induces spontaneous nuclear accumulation of Smad proteins and activation of promoter governed by the SMAD protein complex. TIAF1 aggregates are expressed in degenerating neurons and form plaques in the hippocampus. Most importantly, TIAF1 aggregates possessing $A \beta$ in the hippocampi are significantly increased in postmortem AD patients (age 71-90; $n=97$ ), compared with younger nondemented controls (age 42 to $76 ; n=41$ ), suggesting that formation of TIAF1 aggregation occurs before that of $A \beta$.

Under physiological conditions, $\mathrm{T} \beta \mathrm{R}$ Il has a central role in the TGF- $\beta$ signaling, which involves the TGF- $\beta / \mathrm{Smad} 2 / 3 / 4$ signal complex (see the schematic summary; Figure 8). Recently, we discovered that TGF- $\beta 1$ binds membrane Hyal-2, and the TGF- $\beta 1 /$ Hyal-2 complex recruits tumor 
a Physiological TGF- $\beta$ Signaling b

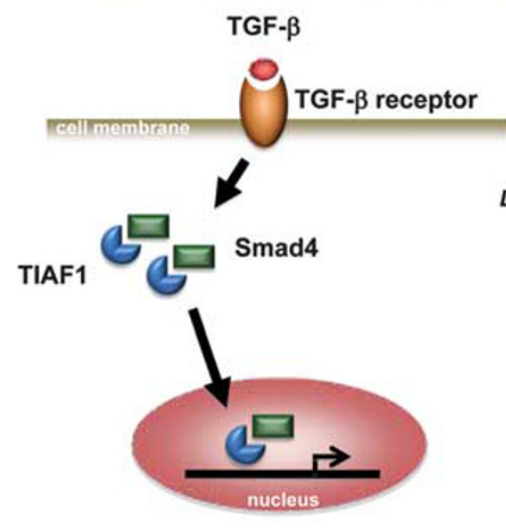

No TIAF1

aggregation
Aberrant TGF- $\beta$ Signaling
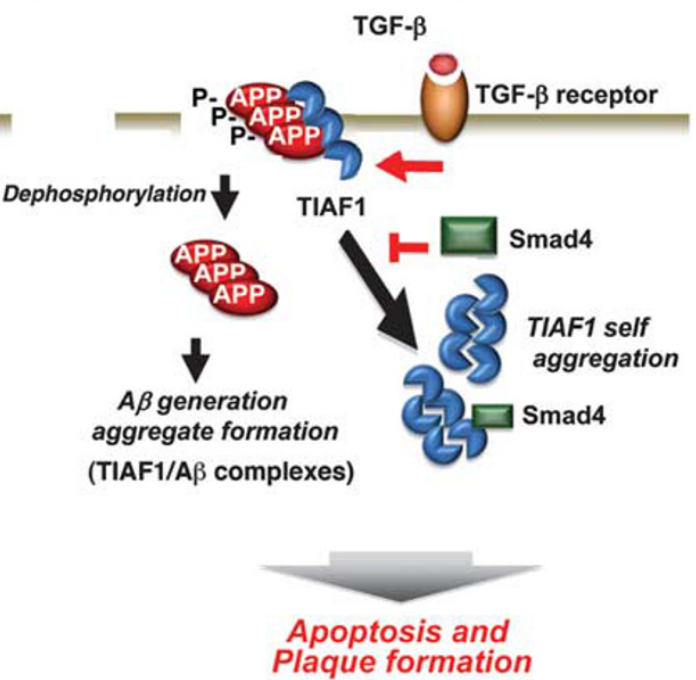

Figure 8 Schematic summary of TGF- $\beta 1$-induced TIAF1 self-aggregation. (a) Under physiological conditions, TGF- $\beta 1$ signals via Smad2/3/4 or hyaluronidase Hyal-2. ${ }^{14}$ Additionally, TGF- $\beta 1$ stimulates the binding of TIAF1 with Smad4 for relocating to the nuclei to regulate gene transcription. Smad4 prevents TIAF1 self-aggregation. (b) Altered TGF- $\beta$ signaling is expected under pathological conditions. TGF- $\beta 1$ signals via TGF- $\beta$ receptors or Hyal-2 for APP fragmentation and TIAF1 self-aggregation. Supporting evidence shows that TIAF1 binds and stabilizes membrane Thr668-phosphorylated APP. TGF- $\beta 1$ reduces the binding, thus leading to APP de-phosphorylation. The dephosphorylated APP undergoes degradation and generation of $A \beta$ monomer, AICD and amyloid fibrils. TIAF1 aggregates form complexes with amyloid fibrils for apoptosis and gradual formation of TIAF1/A $\beta$ plaques. Smad4 may block TIAF1 aggregation. Alternatively, TIAF1 aggregates bind cytosolic Smad4 to prevent nuclear accumulation and apoptosis. Thus, a balanced status of phosphorylation of APP is critical in determining plaque formation

suppressor WOX1 and Smad4 for signaling. ${ }^{14}$ We determined here that TGF- $\beta 1$ signals the binding of TIAF1 with Smad4, and the complex relocates to the nuclei to modulate gene transcription (Figure 8a). Smad4 is critical for supporting the generation of membrane APP via regulation at the gene transcription level. ${ }^{21,22}$ Smad4 prevents TIAF1 selfaggregation. The TGF- $\beta / \mathrm{Smad} 4 / \mathrm{TIAF} 1$ signaling is expected to occur in every normal cell. How TIAF1 affects Smad4 in controlling APP production remains to be established.

TGF- $\beta$ signaling is probably aberrant under pathological conditions (Figure $8 b$ ). ${ }^{2-5,23,24}$ TGF- $\beta 1$ is crucial in promoting neuroprotection and neurodegeneration. ${ }^{24}$ Long-term overexpression of TGF- $\beta 1$ in mice causes neurodegeneration. ${ }^{24}$ TIAF1 interacts with Thr668-phosphorylated APP, suggesting that TIAF1 binds and stabilizes membrane APP. TGF- $\beta 1$ induces TIAF1 aggregation and reduces its binding with APP, and causes APP dephosphorylation. The dephosphorylated APP is subjected to enzymatic cleavage and subsequent production of $\mathrm{A} \beta$ monomer, ${ }^{20} \mathrm{AICD}$ and amyloid fibrils. Aggregated TIAF1 binds amyloid fibrils, which facilitates gradual formation of TIAF1/A $\beta$ plaques. How AICD is generated because of TIAF1 aggregation remains to be established. ${ }^{25}$ AICD is involved in signaling and differentiation of neurons. ${ }^{26}$ Thus, a balanced status of phosphorylation of APP is critical in determining plaque formation.

Neuroblastoma, melanoma and many other cancer cells are refractory to TGF- $\beta$-mediated growth suppression and apoptosis. $^{27,28}$ TGF- $\beta 1$ and $-\beta 2$ could rapidly induce APP degradation and production of $A \beta$ and amyloid fibrils in breast MCF7 and other cancer cells. A $\beta$ appears to be cleared up swiftly in MCF7 cells (data not shown), suggesting a novel mechanism for cancer cells to escape $\mathrm{A} \beta$ cytotoxicity.
Endogenous TIAF1 is prone to aggregate under stress stimuli, which leads to generation of $\mathrm{A} \beta$ and amyloid fibrils. UV light, estrogen and lactacystin inhibit TIAF1 expression, or probably induce its degradation. In vitro analyses showed that overexpressed TIAF1 undergoes self-binding, and TGF- $\beta 1$ enhances the effect. The aggregated TIAF1 appears to cause APP phosphorylation at Thr668, which is located at the $C$-terminal tail of APP presenting in the cytoplasm. By surface plasmon-enhanced TIRF (total internal reflection fluorescence) microscopy, ${ }^{29,30}$ we have recently determined that complement $\mathrm{C} 1 \mathrm{q}$ destabilizes cell adherence by generating dynamic 'turbulence' of plasma membrane in tumor suppressor WOX1-expressing cells. It would be of interest to examine TGF$\beta 1$-mediated membrane turbulence for de-phosphorylating APP and generating $\mathrm{A} \beta$ and amyloid fibrils. Thr668-phosphorylated APP affects the cell metabolism regarding its tendency in generation of $\mathrm{A} \beta$. $^{26,31-33}$

Smad4 physically interacts with TIAF1, and the binding prevents TIAF1 aggregation. Indeed, the concentration of Smad4 is critical in determining the strength of its binding with TIAF1. The overexpressed Smad4/TIAF1 complexes tend to remain in the perinuclear area, thereby abolishing the transcriptional function of Smad4. Overexpressed Smad4 alone induces apoptosis of cancer and neuronal cells. Smad4 is involved in the TGF- $\beta$-induced transcriptional activation of APP gene. ${ }^{21,22}$ Conceivably, TGF- $\beta$-induced TIAF1 aggregation and Smad4-mediated APP gene activation occur concurrently (Figure 8), and that aggregated TIAF1 binds Smad4 to prevent nuclear relocation.

In summary, protein aggregation has a critical role in the pathogenesis of neurodegeneration. ${ }^{33-35}$ Apparently, TIAF1 aggregation occurs preceding generation of $A \beta$ and amyloid 
fibrils, and the TIAF1/amyloid fibril aggregates facilitate plaque formation.

\begin{abstract}
Materials and Methods
Cell lines, postmortem human hippocampi, brain tissue sections, antibodies, immunohistochemistry, fluorescence immunostaining and confocal microscopy. Cell lines used were human neuroblastoma SH-SY5Y and SK-N-SH cells, lung non-small cell lung cancer NCl-H1299 cells, breast cancer MCF7 and MDA-MB-231 cells, colon cancer HCT116 cells, prostate DU145 cells, teratocarcinoma NT2D1 cells, and murine L929 fibroblasts (American Type Cell Collections). Recombinant TGF- $\beta 1$ was from PeproTech (Rocky Hill, NJ, USA). Antibodies against TIAF1 were either homemade ${ }^{6}$ or from Abcam. $A \beta$ antibodies were from (1) $A b D / S e r o t e c$ (MCA2172; Oxford, UK), (2) Covance (6E10; Princeton, NJ, USA) and (3) Santa Cruz Biotechnologies (H43; Santa Cruz, CA, USA). Prefibrillar oligomer A11 antibody ${ }^{36}$ was from Invitrogen (Carlsbad, CA, USA). Amyloid fibril-specific antibody (AO), ${ }^{36}$ APP antibody (MAB348) and Fluoro-Jade C Red were from Chemicon/ Millipore. Antibody against phospho-APP at Thr668 was from Cell Signaling Technology (Danvers, MA, USA). AICD antibody (SIG-39152) was from Covance. $A \beta 42$ and $A \beta 40$ were synthesized by AnaSpec (Fremont, CA, USA). Human postmortem hippocampal tissues, either frozen or on slides, were obtained from the Department of Pathology, University of Colorado Health Sciences Center. Informed consents were obtained from the family members of the deceased patients. Hippocampal tissues of transgenic APP/PS1 and APP only mice were used in this study in accordance with the guidelines of the National Institutes of Health, USA. Immunohistochemistry and fluorescent immunostaining of tissue sections were performed as described. ${ }^{37,38}$
\end{abstract}

Filter retardation assay. Filter retardation assay was performed as described. ${ }^{39}$ Postmortem human frozen hippocampal samples $(\sim 1 \mathrm{mg})$ were homogenized using a lysis buffer (0.5\% NP-40, $0.1 \%$ Triton X-100, $0.1 \%$ SDS in PBS). After centrifugation at 13200 r.p.m. for $30 \mathrm{~min}$ at $4{ }^{\circ} \mathrm{C}$, the pellets were harvested and added $100 \mu \mathrm{l}$ DNase I buffer $(20 \mathrm{mM}$ Tris- $\mathrm{HCl}$, pH 8.0, $15 \mathrm{mM} \mathrm{MgCl} 2,1 \mathrm{mg} / \mathrm{ml} \mathrm{DNase} \mathrm{I),} \mathrm{and} \mathrm{then} \mathrm{incubated} \mathrm{for} 1 \mathrm{~h}$ at $37^{\circ} \mathrm{C}$. Protein preparations were quantified (BCA assay kit, Pierce, Waltham, MA, USA). Each sample, containing 10,30 and $60 \mu \mathrm{g}$ protein, respectively, was diluted in $100 \mu \mathrm{l}$ sample buffer ( $1 \% \mathrm{SDS}, 8 \% \beta$-mercaptoethanol in PBS), boiled for 10 min at $95^{\circ} \mathrm{C}$, and then filtered through $0.2 \mu \mathrm{m}$ cellulose acetate membranes using a dot-blot apparatus (Bio-dot apparatus, Bio-Rad, Hercules, CA, USA). Each well was washed by $200 \mu \mathrm{l} 0.1 \%$ SDS twice. Then, the membranes were analyzed by standard western blotting to determine the presence of $A \beta$ and TIAF1.

cDNA expression constructs and Cytotrap yeast two-hybrid analysis. TIAF1 CDNA was tagged in-frame with EGFP, ECFP or EYFP (in pEGFP-C1, pECFP-C1, pEYFP-C1; Clontech, Mountain View, CA, USA). These constructs were used for cell experiments as specified. To identify TIAF1-binding proteins, TIAF1 was used as a bait protein to screen murine L929 fibroblast CDNA libraries using CytoTrap Ras rescue-based yeast two-hybrid analysis (Stratagene, La Jolla, CA, USA), as described. ${ }^{8,12,13}$ Binding of Smad4 with TIAF1, along with appropriate controls, was performed using the CytoTrap system.

Epifluorescence, time-lapse, confocal microscopy, FRET and cell cycle analysis. Epifluorescence, time-lapse microscopy (Nikon Eclipse TE2000-U; Tokyo, Japan) and confocal microscopy (Olympus (Tokyo, Japan) and Zeiss (Hamburg, Germany)) were performed to test the effect of TGF- $\beta 1$ on protein aggregation and apoptosis. Time-lapse FRET analysis was performed for TIAF1 self-binding and its interaction with Smad4. ${ }^{15,29,30}$ The FRET images were corrected for background fluorescence from an area free of cells. The spectrally corrected FRETc was calculated using a software program (Image-Pro Plus 6.1) by Youvan's equation (Image-Pro 6.1, Media Cybernetics, Bethesda, MD, USA). ${ }^{15,29,30}$ When indicated, cells were transfected with the TIAF1 constructs and cultured for $48 \mathrm{~h}$, followed by determining the extent of apoptosis and growth suppression by cell cycle analysis using a fluorescence-activated cell sorting/flow cytometry machine (BD, Sparks, MD, USA), as described. ${ }^{8,12}$

\section{Conflict of interest}

The authors declare no conflict of interest.
Acknowledgements. Research was supported, in part, by the Department of Defense, USA (BC075692 and NF093068), the National Science Council (NSC), Taiwan, ROC (NSC96-2320-B-006-014, 96-2628-B-006-045-MY3, 96-2628-B-006041-MY3 and 99-2320-B-006-012-MY3), the National Health Research Institute, Taiwan, ROC (NHRI-EX97-9705BI, EX98-9705BI and EX99-9705BI) and the National Cheng Kung University Landmark Projects (C0167 and R026) to N-S Chang; NSC96-2320-B-006-036-MY3 to C-I Sze; NSC98-2320-B-006-007-MY3 and to L-J Hsu; and grants from NIH and Alzheimer's Association to CX Gong.

1. Hanger DP, Anderton BH, Noble W. Tau phosphorylation: the therapeutic challenge for neurodegenerative disease. Trends Mol Med 2009; 15: 112-119.

2. Tesseur I, Zou K, Esposito L, Bard F, Berber E, Can JV et al. Deficiency in neuronal TGFbeta signaling promotes neurodegeneration and Alzheimer's pathology. J Clin Invest 2006; 116: 3060-3069.

3. Salins P, He Y, Olson K, Glazner G, Kashour T, Amara F. TGF-beta1 is increased in a transgenic mouse model of familial Alzheimer's disease and causes neuronal apoptosis. Neurosci Lett 2008; 430: 81-86.

4. Peila R, Yucesoy B, White LR, Johnson V, Kashon ML, Wu K et al. A TGF-beta1 polymorphism association with dementia and neuropathologies: the HAAS. Neurobiol Aging 2007; 28: 1367-1373.

5. Town T, Laouar Y, Pittenger C, Mori T, Szekely CA, Tan J et al. Blocking TGF-betaSmad2/3 innate immune signaling mitigates Alzheimer-like pathology. Nat Med 2008; 14 681-687.

6. Chang NS, Mattison J, Cao H, Pratt N, Zhao Y, Lee C. Cloning and characterization of a novel transforming growth factor-beta1-induced TIAF1 protein that inhibits tumor necrosis factor cytotoxicity. Biochem Biophys Res Commun 1998; 253: 743-749.

7. Khera S, Chang NS. TIAF1 participates in the transforming growth factor beta1-mediated growth regulation. Ann NY Acad Sci 2003; 995: 11-21.

8. Schultz L, Khera S, Sleve D, Heath J, Chang NS. TIAF1 and p53 functionally interact in mediating apoptosis and silencing of TIAF1 abolishes nuclear translocation of serine 15-phosphorylated p53. DNA Cell Biol 2004; 23: 67-74.

9. van der Leij J, van den Berg A, Albrecht EW, Blokzijl T, Roozendaal R, Gouw AS et al. High expression of TIAF-1 in chronic kidney and liver allograft rejection and in activated T-helper cells. Transplantation 2003; 75: 2076-2082.

10. Pfoertner S, Jeron A, Probst-Kepper M, Guzman CA, Hansen W, Westendorf AM et al. Signatures of human regulatory T cells: an encounter with old friends and new players. Genome Biol 2006; 7: R54.

11. Griseri P, Vos Y, Giorda R, Gimelli S, Beri S, Santamaria G et al. Complex pathogenesis of Hirschsprung's disease in a patient with hydrocephalus, vesico-ureteral reflux and a balanced translocation $\mathrm{t}(3 ; 17)(\mathrm{p} 12 ; \mathrm{q} 11)$. Eur J Hum Genet 2009; 17: 483-490.

12. Chang NS, Pratt N, Heath J, Schultz L, Sleve D, Carey GB et al. Hyaluronidase induction of a WW domain-containing oxidoreductase that enhances tumor necrosis factor cytotoxicity. J Biol Chem 2001; 276: 3361-3370.

13. Hong Q, Hsu LJ, Schultz L, Pratt N, Mattison J, Chang NS. Zfra affects TNF-mediated cell death by interacting with death domain protein TRADD and negatively regulates the activation of NF-kappaB, JNK1, p53 and WOX1 during stress response. BMC Mol Biol 2007; 8: 50.

14. Hsu LJ, Schultz L, Hong Q, Van Moer K, Heath J, Li MY et al. Transforming growth factor beta1 signaling via interaction with cell surface Hyal-2 and recruitment of WWOX/WOX1. J Biol Chem 2009; 284: 16049-16059.

15. Kuo YM, Emmerling MR, Vigo-Pelfrey C, Kasunic TC, Kirkpatrick JB et al. Water-soluble Abeta (N-40, N-42) oligomers in normal and Alzheimer disease brains. J Biol Chem 1996; 271: 4077-4081.

16. Bykov VJ, Issaeva N, Shilov A, Hultcrantz M, Pugacheva E, Chumakov $P$ et al. Restoration of the tumor suppressor function to mutant p53 by a low-molecular-weight compound. Nat Med 2002; 8: 282-288

17. Hagn F, Klein C, Demmer O, Marchenko N, Vaseva A, Moll UM et al. BclxL changes conformation upon binding to wild-type but not mutant p53 DNA binding domain J Biol Chem 2010; 285: 3439-3450.

18. Schmued LC, Stowers CC, Scallet AC, Xu L. Fluoro-Jade $C$ results in ultra high resolution and contrast labeling of degenerating neurons. Brain Res 2005; 1035: 24-31.

19. Yan $P$, Bero AW, Cirrito JR, Xiao Q, Hu X, Wang $Y$ et al. Characterizing the appearance and growth of amyloid plaques in APP/PS1 mice. J Neurosci 2009; 29: 10706-10714.

20. Feyt C, Pierrot N, Tasiaux B, Van Hees J, Kienlen-Campard P, Courtoy PJ et al. Phosphorylation of APP695 at Thr668 decreases gamma-cleavage and extracellular Abeta. Biochem Biophys Res Commun 2007; 357: 1004-1010.

21. Burton T, Liang B, Dibrov A, Amara F. Transforming growth factor-beta-induced transcription of the Alzheimer beta-amyloid precursor protein gene involves interaction between the CTCF-complex and Smads. Biochem Biophys Res Commun 2002; 295: 713-723.

22. Docagne F, Gabriel C, Lebeurrier N, Lesne S, Hommet Y, Plawinski L et al. Sp1 and Smad transcription factors co-operate to mediate TGF-beta-dependent activation of amyloid-beta precursor protein gene transcription. Biochem J 2004; 383: 393-399.

23. Tesseur I, Wyss-Coray T. A role for TGF-beta signaling in neurodegeneration: evidence from genetically engineered models. Curr Alzheimer Res 2006; 3: 505-513. 
24. Ueberham U, Ueberham E, Bruckner MK, Seeger G, Gartner U, Gruschka H et al. Inducible neuronal expression of transgenic TGF-beta1 in vivo: dissection of short-term and long-term effects. Eur J Neurosci 2005; 22: 50-64.

25. Kimberly WT, Zheng JB, Town T, Flavell RA, Selkoe DJ. Physiological regulation of the beta-amyloid precursor protein signaling domain by c-Jun N-terminal kinase JNK3 during neuronal differentiation. J Neurosci 2005; 25: 5533-5543.

26. lijima K, Ando K, Takeda S, Satoh Y, Seki T, Itohara $S$ et al. Neuron-specific phosphorylation of Alzheimer's beta-amyloid precursor protein by cyclin-dependent kinase 5. J Neurochem 2000; 75: 1085-1091.

27. Gatza CE, Oh SY, Blobe GC. Roles for the type III TGF-beta receptor in human cancer. Cell Signal 2010; 22: 1163-1174.

28. Flanders KC, Wakefield LM. Transforming growth factor-(beta)s and mammary gland involution; functional roles and implications for cancer progression. J Mammary Gland Biol Neoplasia 2009; 14: 131-144

29. He RY, Su YD, Cho KC, Lin CY, Chang NS, Chang CH et al. Surface plasmon-enhanced two-photon fluorescence microscopy for live cell membrane imaging. Opt Express 2009; 17: 5987-5997.

30. Hong Q, Sze Cl, Lin SR, Lee MH, He RY, Schultz L et al. Complement C1q activates tumor suppressor WWOX to induce apoptosis in prostate cancer cells. PLoS One 2009; 4: e5755.

31. Ando K, lijima KI, Elliott JI, Kirino Y, Suzuki T. Phosphorylation-dependent regulation of the interaction of amyloid precursor protein with $\mathrm{Fe} 65$ affects the production of beta-amyloid. J Biol Chem 2001; 276: 40353-40361.

32. Standen CL, Brownlees J, Grierson AJ, Kesavapany S, Lau KF, McLoughlin DM et al. Phosphorylation of thr(668) in the cytoplasmic domain of the Alzheimer's disease amyloid precursor protein by stress-activated protein kinase $1 \mathrm{~b}$ (Jun $\mathrm{N}$-terminal kinase-3) J Neurochem 2001; 76: 316-320.
33. Kvam E, Nannenga BL, Wang MS, Jia Z, Sierks MR, Messer A. Conformational targeting of fibrillar polyglutamine proteins in live cells escalates aggregation and cytotoxicity. PLoS One 2009; 4: e5727.

34. Stefani M. Protein folding and misfolding on surfaces. Int J Mol Sci 2008; 9: 2515-2542.

35. Sugaya K, Matsubara S. Nucleation of protein aggregation kinetics as a basis for genotypephenotype correlations in polyglutamine diseases. Mol Neurodegener 2009; 4: 29.

36. Kayed R, Head E, Sarsoza F, Saing T, Cotman CW, Necula M et al. Fibril specific, conformation dependent antibodies recognize a generic epitope common to amyloid fibrils and fibrillar oligomers that is absent in prefibrillar oligomers. Mol Neurodegener 2007; 2: 18

37. Lo CP, Hsu LJ, Li MY, Hsu SY, Chuang JI, Tsai MS et al. MPP+-induced neuronal death in rats involves tyrosine 33 phosphorylation of WW domain-containing oxidoreductase WOX1. Eur J Neurosci 2008; 27: 1634-1646.

38. Li MY, Lai FJ, Hsu LJ, Lo CP, Cheng CL, Lin SR et al. Dramatic co-activation of WWOX/ WOX1 with CREB and NF-kappaB in delayed loss of small dorsal root ganglion neurons upon sciatic nerve transection in rats. PLOS One 2009; 4: e7820.

39. Heiser V, Scherzinger E, Boeddrich A, Nordhoff E, Lurz R, Schugardt N et al. Inhibition of huntingtin fibrillogenesis by specific antibodies and small molecules: implications for Huntington's disease therapy. Proc Natl Acad Sci USA 2000; 97: 6739-6744.

Cell Death and Disease is an open-access journal published by Nature Publishing Group. This work is licensed under the Creative Commons Attribution-Noncommercial-No Derivative Works 3.0 Unported License. To view a copy of this license, visit http://creativecommons.org/licenses/by-nc-nd/3.0/

Supplementary Information accompanies the paper on Cell Death and Disease website (http://www.nature.com/cddis) 